\title{
EFECE sistemleri
}

\section{EFECE systems}

\author{
Emre Karadeniz \\ Kocaeli Üniversitesi Tıp Fakültesi, Ortopedi ve Travmatoloji Ana Bilim Dalı, Kocaeli
}

EFECE Sistemleri; EFECE tel tutucusu, EFECE teli ve EFECE el aletlerinden oluşan yeni bir kırık tespit yöntemidir. EFECE Tel Tutucusu: Silindir şeklinde, ortasında EFECE teli için delik bulunan ve birbirine yivler aracılığı ile geçen iki parçadan oluşmaktadır. Üstteki parça bir kapak olarak fonksiyon görmektedir. Alttaki parça ise üç adet topun yerleşmesi için üç adet huni şeklinde oluk içermektedir. Kilitleme mekanizması, huni şeklindeki oluklara yerleştirilen toplar sayesinde gerçekleşmektedir. İleri doğru harekette toplar huni şeklindeki oluğun daha geniş olan tabanına doğru hareket etmekte ancak geri doğru çekildiğinde ise toplar huni şeklindeki olukların dar olan kısmına sıkışmakta ve EFECE telinin hareket etmesine izin vermemektedir. EFECE teli: EFECE tel tutucusu içindeki toplara uygun sertlikte üretilmiş Kirschner telidir. EFECE el aletleri: Tamamen perkütan uygulama için tasarımı yapılmış tel üzerinden gönderilen zıvana, çalışma kanülü, dış yakalayıcı, tornavida, kompresör, tel kesme, mıknatıs, mandal ve top çıkartıcı el aletlerinden oluşmaktadır.

Anahtar sözcükler: kırık tespiti; internal tespit; implant; osteosentez

\section{T. C. Türk Patent Enstitüsü'ne Faydalı Model Belgesi için Başvuru Bilgileri ${ }^{[1]}$}

Başvuru bilgileri Tablo 1'de gösterilmiştir. ${ }^{[1]}$

Tablo 1. Başvuru bilgileri[1]

$\begin{aligned} \text { Başvuru numarası: } & \text { a2010 } \backslash 05662 \\ \text { Başvuru tarihi: } & 12.07 .2010 \\ \text { Başvuru şekli: } & \text { Ulusal başvuru } \\ \text { Başvuru Yayın No: } & \text { TR } 2010 \text { 05662 A1 } \\ \text { Başvuru Yayın Tarihi: } & 23.01 .2012 \\ \text { Patent Belgesinin Veriliş Tarihi: } & 22.04 .2013 \\ \text { Koruma tipi: } & \text { Incelemeli patent } \\ \text { Başvuru sahipleri: } & \text { Emre Karadeniz } \\ \text { Buluş sahipleri: } & \text { Emre Karadeniz }\end{aligned}$

EFECE Systems are a new innovative way of fracture fixation and compose of 3 components: EFECE wire retainer, EFECE wire and EFECE hand set. EFECE Wire Retainer: Cylinder shaped and has a hole for insertion of EFECE wire. It consists of 2 parts that catch each other by threads. Upper part functions as a cap. Lower part has 3 cone shaped grooves for insertion of 3 balls. Locking mechanism is with the help of the balls in the cone shaped grooves. During forward movement on EFECE wire, balls move to the base of the cone which is wider and release the EFECE wire. Though, during backward movement, balls jam at the narrow part of cone shaped grooves and lock the EFECE wire. EFECE Wire: A kind of Kirschner wire which is produced with suitable hardness for EFECE wire retainer. EFECE Hand Set: Includes sleeve, working canul, outer catcher, screw driver, compressor, wire cutter, magnet, latch and ball removers. All hand set designed for percutaneous technique.

Key words: fracture fixation; internal fixation; implant; osteosynthesis

\section{FAYDALI MODEL BELGESI - No: 2010 05662[1] BIR TEL TUTUCUSU}

\author{
Teknik Alan ${ }^{[1]}$
}

"Bu buluş kırıkların tedavisinde kullanılan bir tel tutucusu ile ilgilidir. ${ }^{[1] "}$

\section{Önceki Teknik/Teknikler ${ }^{[1]}$}

“Kırıkların cerrahi tedavisinde günümüze kadar geliştirilen teknikler; Kirschner teli (K-teli), vida, plak-vida, intramedüller çivi ve dışarıdan (eksternal) tespittir. Anılan tüm tekniklerde amaç kırık iyileşmesi sağlanıncaya kadar kırık parçalarını istenilen şekilde tutmaktır. Bu tekniklerin avantaj ve dezavantajları kırık tiplerine göre değişmekte ve cerrahın tedavi planını şekillendirmektedir.

- İletişim adresi: Dr. Emre Karadeniz, Kocaeli Üniversitesi Tıp Fakültesi, Ortopedi ve Travmatoloji Ana Bilim Dalı, Umuttepe Kampüsü, İzmit, Kocaeli Tel: 0532 - 2816850 e-posta: ekaradenizmd@gmail.com ORCID iD: 0000-0002-6181-3836

- Geliş tarihi: 15 Kasım $2020 \quad$ Kabul tarihi: 7 Aralık 2020 
Bu tekniklerden, K-teli ile tespitte; kırık yerine oturtulduktan (redüksiyon) sonra bu düz teller kemik parçaları arasından geçirilerek kırık sabitlenmektedir. Redüksiyon sonrası bu tellerin kırık parçaları arasında basınç (kompresyon) sağlayamaması nedeni ile tel boyunca parçaların ileri geri hareket edebilmeleri bu tekniğin en önemli kısıtlayıcısıdır. Ayrıca bu teller vücuda yerleştirildikten sonra hareket edebilmektedir.

Kırıkların vida ile tespitinde ise; kırık parçaları öncelikli olarak yerine oturtulur. Vidanın çalışma mekanizması olan; vida başı ile vida yivleri arasında karşılıklı kuvvet oluşturma esasına göre parçalar arasında kompresyon elde edilir. Bu teknikte, parçalar arasında kompresyon kuvvetini ve tutunmayı arttırmak için vida boyutunu arttırmak gerekmektedir. Kemik parçaları küçük ise vida boyutu arttırılamaz. Vida boyutu nedeni ile parçalar arasına ek vida yerleştirecek yer kalmayabilir. Ayrıca cerrahi teknik olarak vida uygulamak için öncelikle kemikte matkap ile yer açlır (drilleme), sonra vida yivleri için oluk açılır (tepleme) sonrasında vida yerleştirilir. Bu işlemler öncesinde ek olarak bazen vidaya kılavuzluk etmesi için K-telinin yerleştirilmesi gerekmektedir. Sonuç olarak cerrahi teknik göreceli olarak zordur. Ayrıca vida yivleri ile sağlanmaya çalısıllan tutunma kemik erimesi olan hastalar için mümkün olmamaktadır.

Kırıkların plak vida ile tespitinde; redüksiyon sonrası kırık parçaları vida ile tutturulan plaklar yardımı ile yerlerine sabitlenmektedir. Ancak plak tutunması vidalar yardımı ile yapıldığından vidaların uygulanmasındaki tüm dezavantajlar burada da mevcuttur. Plak yerleştirilmesi daha fazla kemik çevre dokusu sıyrılmasını gerektirir ve bu da daha fazla kesi ve kemik parçaları için daha fazla beslenme sorunu demektir. Plak, cilt altı dokusunun az olduğu yerlerde cilt kapanmasına engel olabilir ve ele gelebilmektedir. Kemik parçalar küçük veya ekleme çok yakın olduğunda plak yerleştirilmesi mümkün olmamaktadır. Ayrıca plakların çıkartılması gerektiğinde çevre dokulara tekrar zarar verilmektedir.

Tekniğin bilinen durumunda yer alan US5529075 sayılı Birleşik Devletler patent dokümanında, özellikle ayak parmaklarındaki çarpıklıkları düzeltmek için tasarlanmış bir sabitleme aparatından bahsedilmektedir.

Tekniğin bilinen durumunda yer alan US 5443464 (A) sayılı Birleşik Devletler patent dokümanında, kemik kırılmalarında kemiği sabitleyecek bir destek mekanizmasından bahsedilmektedir."

\section{Buluşun Kısa Tarifi ${ }^{[1]}$}

"Bu buluşun amacı kırıkların tedavisinde kullanılan tellerin kemikler üzerinde sabit durmasını sağlayan bir manyetik aktif tutucu gerçekleştirmektir.

Geliştirilen bu yeni yöntem ile kırıkların tedavisinde sağlanan en temel fayda; redüksiyon sonrası tespitin ince teller yardımı ile kırık hattında kompresyon yapılarak sağlanmasıdır. Böylece, çok kü̧̈ük kırık parçaları komprese edilebilmekte, çok sayıda yerden tespit gerektiğinde ortopedi ve travmatoloji alanındaki cerrahide günümüze kadar tanımlanmış olan tedavi seçeneklerinden çok daha fazla sayıda tespit sağlanabilmektedir. Buluş konusu tutucu ile ince k-tellerinin hem kompresyon hem destek amaçlı kullanılabilmesi sağlanmaktadır. Diz çevresi gibi ekleme yakın yerleşimli kırıklarda önemli sorun olan küçük parçaların çökmesi sorununu ortadan kaldırması amacı ile tedavide kullanılabilmektedir. Vida deliklerinden kaynaklanan kemik doku hasarı sonrası görülen yeni kemik kırılmaları sorunu, aynı tutunma ince k-telleri ile sağlanacağından çok daha az görülecektir. Dirsek çevresi kırıkları gibi kemik anatomisinin kalın tespit araçlarına izin vermediği durumlarda, tutucu ile tel üzerinden kompresyon sağlamak çok önemli bir kullanım avantajı ve bu kırıkların tedavisinde yeni bir ufuk olacaktır. Geliştirilmiş tamamen perkutan teknik sayesinde kemik ve çevre yumuşak dokulara çok daha az hasar vererek kırıkların tedavisi gerçekleştirilebilmektedir. Tepleme ve drilleme işlemlerine gerek duyulmadığından cerrahi çok daha kolay ve kısa süreli olmaktadır. Buluş konusu tutucunun boyutları vida başları büyüklügünde olduğundan tutucu kırık üzerine yerleştirilen plaklara göre çok daha az yer kaplamakta ve tutucunun cilt altında ele gelme sorunu çok daha az görülmektedir. Vidalarda yivler ile sağlanmaya çalışılan kompresyon kuvveti, kemik iliği tutunması gerektirdiğinden kemik kalitesi düşük hastalarda kullanım zorluklarına yol açmakta iken buluş konusu tutucu ile kemik korteksi üzerinden tutunma sağlandığından osteoporoz gibi kemik kalitesinin düşük olduğu hastalarda çok önemli kullanım avantajları getirmektedir. Yine bu tutucular ile kortikal tutunma sağlandığından tutucuların çıkması sorunu görülmemektedir. Tutucuların kırık tedavisi sonrası çıkartılması çok daha az kemik ve çevre yumuşak doku hasarı ile ve mıknatıslar yardımı ile çok daha kolay yapılabilmektedir."

\section{Buluşun Detaylı Açıklaması ${ }^{[1]}$}

"EFECE Tel Tutucusu: Silindir şeklinde, ortasında EFECE teli için delik bulunan ve birbirine yivler aracılığı ile geçen iki parçadan oluşmaktadır. Üstteki parça bir kapak olarak fonksiyon görmektedir. Alttaki parça ise 3 adet topun yerleşmesi için 3 adet huni şeklinde oluk içermektedir. (Şekil 1) Kilitleme mekanizması, huni şeklindeki oluklara yerleştirilen toplar sayesinde gerçekleşmektedir. Ileri doğru harekette toplar huni şeklindeki oluğun daha geniş olan tabanına doğru hareket etmekte ancak geri doğru çekildiğinde ise toplar huni şeklindeki olukların dar olan kısmına sıkışmakta ve EFECE telinin hareket etmesine izin vermemektedir.

Buluş konusu tutucu, somun şeklinde, bir yüzeyi kapalı diğer yüzeyi ise bağlantı için açık bırakılan en az bir üst parça, üst parçanın merkezinde yer alan en az bir boşluk, üst 
parçanın bağlantısını sağlayan tercihen yivli en az bir bağlantı yüzeyi, üst parçaya bağlantı yüzeyi vasıtası ile bağlanan, bă̆lantı yüzeyi ile temas eden yüzeyinde tercihen yiv bulunan, silindirik şekilde en az bir uzantı, uzantı üzerinde yerleştirilen, alt parçanın hareket ettirilmesini sağlayan, üst parçanın kapalı yüzeyi ile paralel olan ve boşluk ile eş merkezli en az bir boşluğa sahip en az bir çıkıntı, boşluk ile eş merkezli bir çember üzerinde yerleştirilmiş, uzantı boyunca uzanan, tercihen çıkıntıya doğru daralan koni şeklinde en az bir yuva içeren en az bir alt parça, yuvaya yerleştirilen tercihen küre şeklinde en az bir bilye içermektedir.

Buluşun tercih edilen uygulamasında alt parça aralarındaki açılar eşit olacak şekilde yerleştirilmiş üç yuva içermektedir. Bu uygulamada yuvaların her biri içerisinde bir bilye bulunmaktadır.

Buluşun tercih edilen uygulamasında üst parça altı köşe somun şeklindedir. Buluşun bir diğer uygulamasında alt parça ve üst parça birbirlerine bir klips mekanizması ile kenetlenmektedir. Buluşun bir diğer uygulamasında çıkıntı uzantının yan yüzeyine teğet ve birbirine paralel iki kesik içermektedir. Bu kesikler çıkıntının daha rahat kavranmasını sağlamaktadır.

Tutucu kırık tespiti sonrası, istenen pozisyonda yerleştirilen $K$-teli üzerinden kemik parçalarının her iki tarafindan yerleştirilmektedir. Tutucu kırık hattında kompresyon yapacak şekilde sıkıştırılmakta ve sonrasında üst parça ve alt parça döndürülerek kilitlenmektedir.

Tutucu kırıklarda kompresyon yönünde rahat hareket ederken gevşeme yönündeki hareketler koni şeklindeki yuva içerisinde yuvanın dar kısmına doğru hareket eden bilyelerin teli sıkışırması sayesinde engellenmektedir.

Kilitlenme işleminden sonra K-tellerinin tutucudan taşan kııımları kesilmektedir. Böylece kırık tespiti işlemi sonlanmış olmaktadır. Kırık iyileşme süreci tamamlandıktan sonra, tutucuların çıkartılması için tutucuların üzerinden yapılan küçük kesiler ile tutuculara ulaşılmakta, daha sonra üst parça ve alt parça bağlantısı hafifçe gevşetilmektedir. Tutuculara yaklaştırılan bir mıknatıs yardımı ile tutucu içerisindeki bilyeler yuvanın geniş olan tarafina doğru çekilmekte ve tutuси K-telinden kurtulmaktadır, sonrasında K-teli çekilerek çıkartılmaktadır.”

\section{İstemler ${ }^{[1]}$}

"1. Somun şeklinde, bir yüzeyi kapalı diğer yüzeyi ise bağlantı için açık bırakılan en az bir üst parça, üst parçanın merkezinde yer alan en az bir boşluk, üst parçanın bă̆lantısını sağlayan tercihen yivli en az bir bağlantı yüzeyi, üst parçaya bağlantı yüzeyi vasıtası ile bağlanan en az bir alt parça içeren ve bağlantı yüzeyi ile temas eden yüzeyinde tercihen yiv bulunan, silindirik şekilde en az bir uzantıya, uzantı üzerinde yerleştirilen, alt parçanın hareket ettirilmesini sağlayan, üst parçanın kapalı yüzeyi ile paralel olan ve boşluk ile eş merkezli en az bir boşluğa sahip en az bir çıkıntıya, boşluk ile eş merkezli bir çember üzerinde yerleştirilmiş, uzantı boyunca uzanan, en az bir yuvaya sahip en az bir alt parça ve yuva içerisine yerleştirilen en az bir bilye ile karakterize edilen bir tel tutucusu.

2. Çıkıntıya doğru daralan koni şeklinde en az bir yuva içeren bir alt parça ile karakterize edilen istem 1'deki gibi bir tel tutucusu.

3. Altı köşe somun şeklinde bir üst parça ile karakterize edilen yukaridaki istemlerden herhangi birindeki gibi bir tel tutucusu.

4. Daha rahat kavranmasını sağlayan, uzantının yan yüzeyine teğet ve birbirine paralel iki kesiğe sahip bir çıkıntı ile karakterize edilen yukarıdaki istemlerden herhangi birindeki gibi bir tel tutucusu."

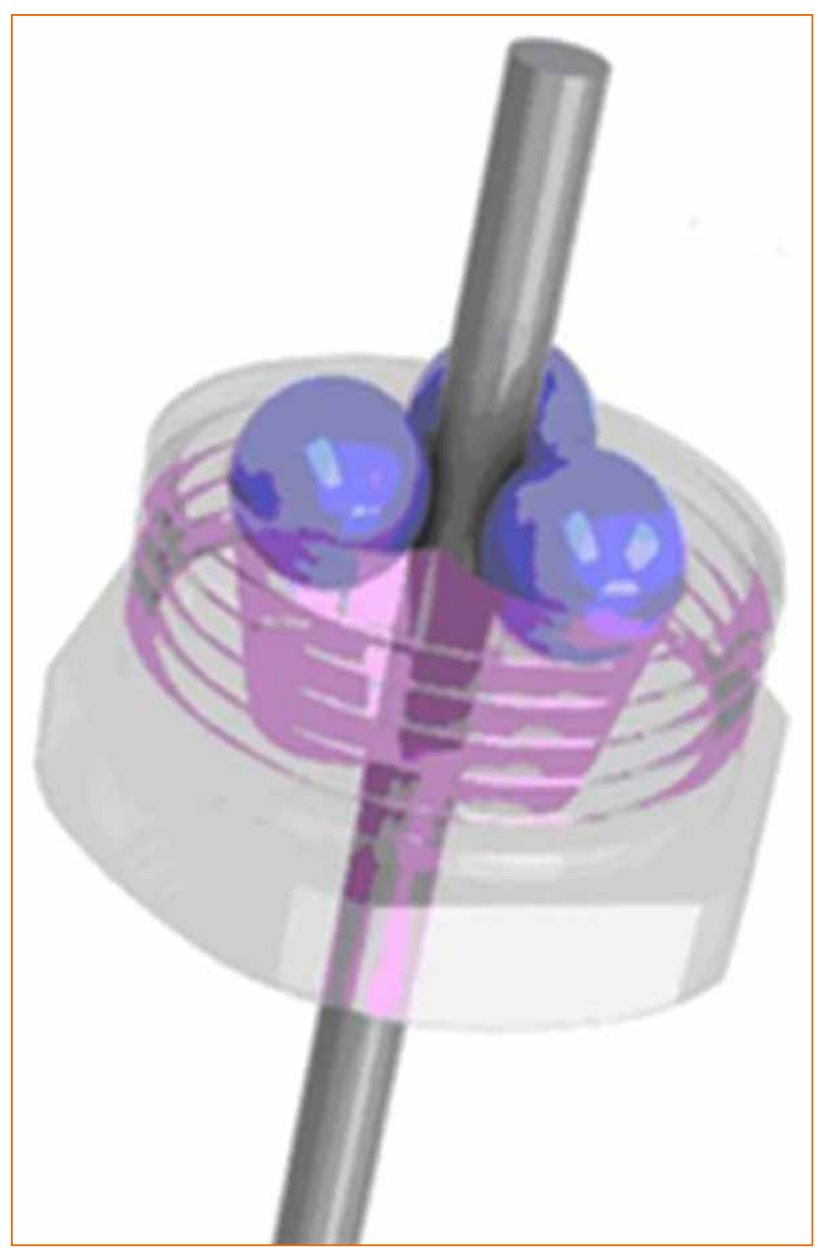

Şekil 1. EFECE tel tutucusu kilitleme mekanizması, huni şeklindeki oluklara yerleştirilen toplar sayesinde gerçekleşmektedir. İleri doğru harekette toplar huni şeklindeki oluğun daha geniş olan tabanına doğru hareket etmekte ve EFECE telini gevşetmektedir. Ancak EFECE tel tutucusu geri doğru çekildiğinde; toplar huni şeklindeki olukların dar olan kısmına sıkışmakta ve EFECE telinin kilitlemektedir. 


\section{EFECE SISTEMLERi}

EFECE sistemleri; EFECE tel tutucusu, EFECE teli ve EFECE el aletlerinden oluşan yeni bir kırık tespit yöntemidir.

EFECE sistemleri gerek Türkiye'yi temsilen tanıtıldığı uluslararası inovasyon fuarlarında, gerek Türkiye'de düzenlenen uluslararası inovasyon fuarlarında birçok ödül kazanmıştır. Bu ödüller: İsviçre'nin Cenevre kentinde 2013 yılında düzenlenen Uluslararası İnovasyon Fuarı'nda: Best Invention Prize "Gümüş Madalya" ve Charity Foundation for Special Diseases of Iran "The Best Invention Prize" ödülleri ile İstanbul'da 2016 yılında düzenlenen Uluslararası Buluşlar Fuarı'nda, Türk Patent Enstitüsü'nün 'En İyi Yerli Buluş Özel Ödülü' , 'Altın Madalya' ve Hırvatistan tarafindan verilen 'ARCA Internatinal Innovation Exhibition Award' ödülleridir.

EFECE tel tutucusu ve kırık hattında kompresyon sağlayan el aletinin Türkiye, Avrupa'da 9 ülke (İngiltere, Almanya, İspanya, Fransa, İtalya, Belçika, Hollanda, Polonya ve İsviçre) ve Amerika Birleşik Devletleri patent validasyon işlemleri tamamlanmıştır. ${ }^{[2] "}$

\section{CERRAHI TEKNIK}

EFECE sistemleri için geliştirilen el aletleri sayesinde tamamen perkütan teknikler ile kırık tespiti ve implant çıkartılması sağlanmaktadır. Cerrahi işlem esnasında yapılması gereken işlemler aşağıdaki sıra ile yapılmalıdır.

a) Kırık hattı ve kırık parçalarının redüksiyonu sonrası redüksiyon klempi ile geçici tespit sağlanır.

b) EFECE telini kırık tespiti için kemikten geçirilir (Şekil 2).

c) Ciltte EFECE telinin giriş ve çıkış yerlerine küçük insizyonlar açılır.

d) EFECE teli üzerinden zıvana (sleeve) kemiğe kadar ilerletilir (Şekil 2).

e) Çalışma kanülünü zıvana üzerinden kemiğe kadar ilerletilir ve zıvana çıkartılır.

f) EFECE teli üzerinden, EFECE tel tutucusu yüklenmiş olan tornavida ve dış yakalayıcıyı çalışma kanülünden kemiğe kadar ilerletilir (Şekil 3).

g) EFECE dış yakalayıcısı sabit tutulurken tornavida sıkıştırılır (Şekil 4).

h) Çalışma kanülü, dış yakalayıcı ve tornavida çekilerek çıkartılır.

i) EFECE teli diğer ucunda "d", "e", "f" işlemleri tekrarlanır.

j) EFECE kompresör cihazı tel üzerinden tornavidaya monte edilerek, EFECE teli yakalanır. k) EFECE kompresör cihazını döndürerek kırık hattında istediğin kadar kompresyon sağlanır.

I) EFECE dış yakalayıcı sabit tutulurken tornavida sıkıştırılır.

m) EFECE kompresör cihazı gevşetilerek çıkartılır.

n) Çalışma kanülü, dış yakalayıcı ve tornavida çekilerek çıkartılır.

o) EFECE perkutan tel kesme cihazı ile tellerin fazlalık kısmı kesilir.

p) Cilt kapatılır.

r) Diğer teller için yukarıdaki işlemler tekrarlanır.

Kırık kaynamasını takiben implant çıkartmak için yapılan girişim esnasındaki işlemler aşağıdaki sıra ile yapılmalıdır.

a) EFECE tel tutucusuna ulaşılması sonrası çalışma kanülü yerleştirilir.

b) Dış yakalayıcı ve tornavida ile EFECE tel tutucusu yakalanır.

c) Dış yakalayıcı sabit durur iken tornavidayı döndürerek EFECE tel tutucusu gevşetilir.

d) Dış yakalayıcı ve tornavida çıkartılır.

e) Çalışma kanülüne mıknatıs yerleştirilir ve EFECE tel tutucusu çalışma kanülünden çıkartılır.

f) EFECE telinin diğer ucundaki EFECE tel tutucusuna ulaşıır.

g) EFECE mandalı ile EFECE tel tutucusu yakalanır.

h) EFECE tel tutucusu ve EFECE teli, EFECE mandalı ile çekerek çıkartılır.

i) Cilt kapatılır.

\section{BIYOMEKANIK DEĞERLENDIRME}

Patella kırıklarında EFECE sistemlerinin davranışını değerlendirmek amacı ile çalışma planlandı.. ${ }^{[3]}$ Kadavralarda patella transvers kırık simulasyonu oluşturuldu. Bir grupta geleneksel gergi bandı yöntemi ile kırık tespiti sağlanırken diğer grupta ise EFECE sistemi ile tespit sağlandı. Her iki gruba artan distraksiyon kuvveti uygulanarak (Şekil 5) elde edilen maksimum kurvet ve bu kuvvet esnasındaki toplam uzama miktarı ölçüldü. (Şekil 6)

Her iki grup için yapılan beşer adet deney sonrasında; EFECE sistemleri ile ortalama maksimum kuvet $740 \mathrm{~N}(720-810 \mathrm{~N})$ iken, gergi bandı yönteminde $330 \mathrm{~N}(240-510 \mathrm{~N})$ idi. EFECE sistemlerinde ortalama uzama $2,5 \mathrm{~mm}(1,6-2,5 \mathrm{~mm})$ iken, gergi bandı yönteminde $3,4 \mathrm{~mm}(2,2-3,8 \mathrm{~mm})$ idi. 


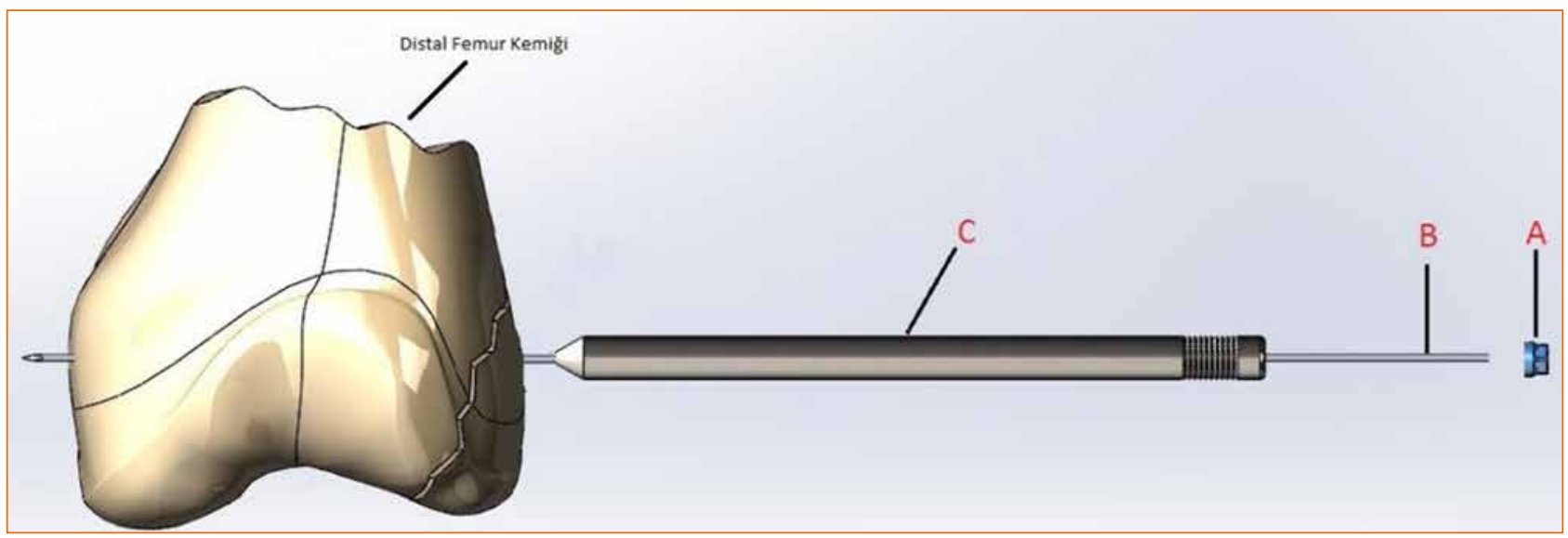

Şekil 2. Femur distal uç kırı̆ı̆ redüksiyonunu takiben 1 adet EFECE teli geçirilmesini takiben zıvananın (sleeve) yerleştirilmesi için ciltte küçük bir insizyon açılır ve zıvana kemiğe kadar ilerletilir. Bu işlemde amaç çalışma kanülünün yerleştirilmesi için bir alan açmaktır.

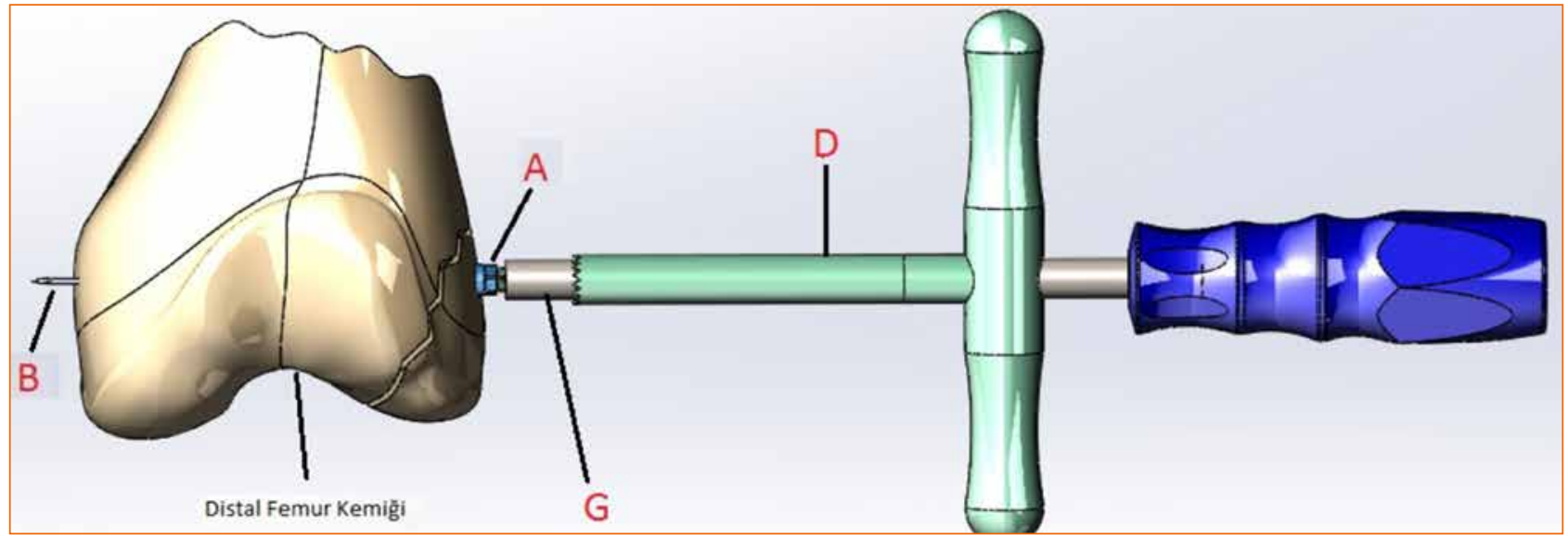

Şekil 3. Çalışma kanülünün zıvana (sleeve) üzerinden kemiğe kadar ilerletilmesinden sonra, EFECE tel tutucusu yüklenmiş dış yakalayıcı ve tornavida çalışma kanülü içinden kemiğe kadar ilerletilir ve dış yakalayıcı sabit tutulurken tornavida döndürülerek EFECE tel tutucusu ve EFECE teli sıkıştırılır.

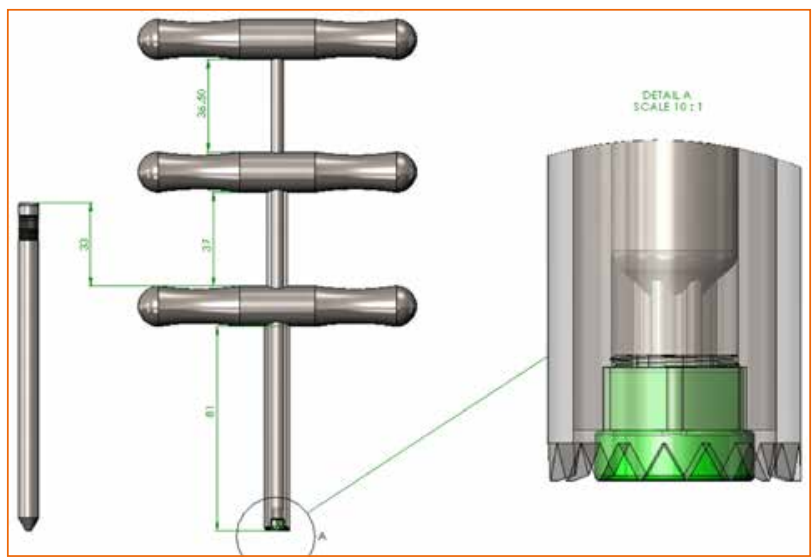

Şekil 4. EFECE dış yakalayıcısı EFECE tel tutucusunun alt parçasını yakalar. Tornavida ise EFECE tel tutucusunun üst parçasını yakalar. Dış yakalayıcı sabit tutulur iken tornavidanın döndürülmesi ile EFECE tel tutucusu üst parçası, alt parçayı ve topları sıkıştırır.

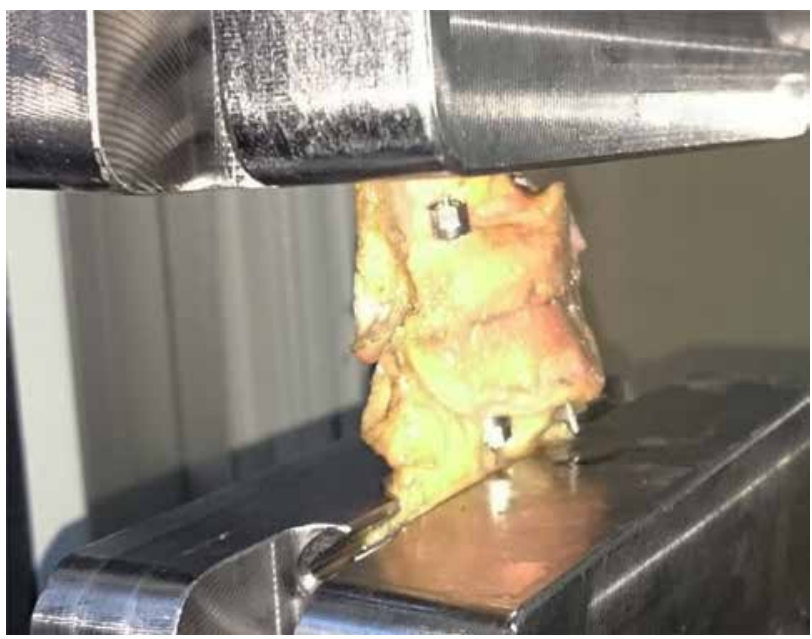

Şekil 5. Gergi bandı ve EFECE sistemleri ile tespit edilen kadavra patella transvers kırık simulasyonlarına artan distraksiyon kuvveti uyguland. 


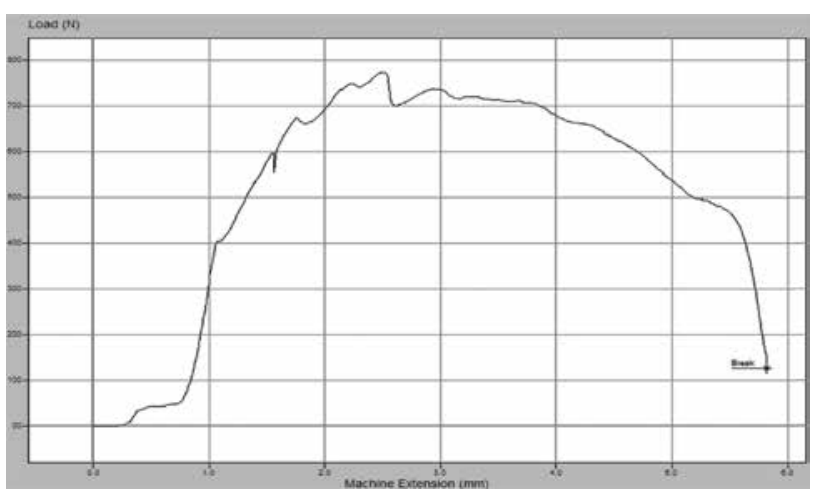

Şekil 6. Germe testleri sonucunda elde edilen grafikte; en yüksek germe kuweti ve bu esnada elde edilen uzama görülmektedir.

İstatistiksel olarak EFECE sistemleri lehine elde edilen tespit kurvetinde anlamlı farklılık var iken $(p=0,008)$, ortalama uzama yönünden gruplar arasında anlamlı farklılık yok idi $(p=0,095)$.
Sonuç olarak EFECE sistemleri patella kırıklarının tespitinde geleneksel yöntemlerimizden çok daha fazla tutunma sağlamaktadır ve çalışma prensipleri nedeni ile cerrahide birçok kullanım alanına sahiptir. Perkütan tekniği ve ince teller üzerinden kompresyon sağlaması nedeni ile mevcut cerrahi çözümlerimize yepyeni bir bakış açısı getirecektir. EFECE sistemlerinin cerrahi sonuçları hastalar için yeni ve değerli veriler sağlayacaktır.

\section{KAYNAKLAR}

1. BirTel Tutucusu. T.C. Türk Patent Enstitüsü. İncelemeli Patent Belgesi. No: TR 2010/05662. https://portal.turkpatent.gov. tr/anonim/arastirma/patent/detayli

2. A Wire Stretcher for Kirschner Wire Passing Trough Wire Retainers. United States Patent Application Publication. No: US 2018 / 0064473 A1. https://www. freepatentsonline.com/ y2018/0064473.html

3. Karadeniz E, Keskinöz EN. A comparison of EFECE systems with tension band wiring for patella fracture fixation in cadavers. J Orthop Surg Res 2020;15:256. Crossref 